trials of treatment of proved urinary tract infection in this age group ${ }^{12}$ have failed to show any benefit from either urethral dilatation or internal urethrotomy.

In adults control of bacterial infection by appropriate advice on fluid loading, frequent voiding, and attention to vulval hygiene together with appropriate antibiotic treatment will alleviate symptoms in most women with bacteriuria. ${ }^{3}$ In a very few cases of persistent urinary tract infection surgery may be necessary to deal with infective calculi or functionless pyelonephritic kidneys.

In the abacteriuric group it is important to try to identify the cause of the syndrome. A third of the patients will show evidence of bladder instability on cystometry, ${ }^{4}$ and anticholinergic drugs such as propantheline, emepromium bromide, or flavoxate hydrochloride may be effective. In the postmenopausal patient with senile vaginitis and urethritis symptoms may be relieved by a course of local or systemic oestrogens. The elimination of vaginal infections, careful instruction in personal hygiene, the maintenance of a good fluid intake, frequent and complete bladder emptying, and voiding after sexual intercourse have all been shown to be beneficial. A few women improve when they stop using vaginal deodorants, bubble baths, and biological washing powders. Nevertheless, there is good evidence that a group remains in whom the symptoms have a functional element, ${ }^{5}$ and psychotropic drugs such as amitryptyline or diazepam may be effective. These women benefit as much from the central effect of such drugs as from their peripheral anticholinergic effects on the bladder.

The role of bladder outflow obstruction in causing symptoms in both the bacteriuric and abacteriuric groups has been much debated. The assumption that outflow obstruction is an important factor in girls with urinary tract infection has not been borne out in two prospective studies, ${ }^{12}$ but there have been reports of the beneficial effects of urethral dilatation or urethrotomy. ${ }^{6}$ A recent report, ${ }^{7}$ however, recommends distal urethroplasty in all groups irrespective of age or the results of bacteriological studies. Like Richardson, who originally advocated urethroplasty in $1969,{ }^{8}$ these workers failed to distinguish between bacteriuric and abacteriuric patients in different age groups, and the urodynamic data on which their diagnosis of outflow obstruction was based were inadequate. A prospective study that compared different indices of outflow obstruction found no evidence of obstruction in $92 \%$ of 156 bacteriuric and abacteriuric patients aged 17 to $69 .{ }^{4}$ Evidence for obstruction in the remaining $8 \%$ was not convincing. This study highlighted the difficulty of correlating static measurements of outflow obstruction with functional changes that may occur during voiding.

Residual urine encourages lower urinary tract infection, ${ }^{9}$ and a degree of outflow obstruction probably occurs in at least some patients with lower urinary tract infection. There is no evidence that this obstruction represents a fixed condition, but the possibility that some degree of reversible spasm occurs, akin to that which is seen in the anal sphincter in patients with an anal fistula, remains to be evaluated.

Patients with recurrent dysuria and frequency warrant thorough investigation so that appropriate treatment may be given. When all else fails, urethral dilatation or urethrotomy may succeed in relieving the symptoms in both bacteriuric and abacteriuric patients, but no other form of urethral surgery seems to be indicated.

${ }^{1}$ Hendry, W F, Stanton, S L, and Innes Williams, D, British fournal of Urology, 1973, 45, 72.
${ }^{2}$ Kaplan, G W, Sammons, T A, and King, L R, fournal of Urology, 1973, $100,917$.

${ }^{3}$ Asscher, A W, British Medical fournal, 1977, 1, 1332.

${ }^{4}$ Rees, D L P, et al, British fournal of Urology, 1975, 47, 853.

${ }^{5}$ Rees, D L P, and Farhoumand, N, British fournal of Urology, 1977, in press.

${ }^{6}$ Farrar, D J, Alan Green, N, and Handley Ashken, M, British fournal of Urology, 1973, 45, 610 .

'Splatt, A J, and Weedon, D, British fournal of Urology, 1977, 49, 173.

${ }^{8}$ Richardson, F H, and Stonington, O G, Surgical Clinics of North America, 1969, vol 49, 1201.

${ }^{9}$ Shand, D G, et al, British fournal of Urology, 1968, 40, 196.

\section{Screening children for visual defects}

Nowhere are the opportunities for preventive medicine better than in the treatment of amblyopia, whether it be associated with a squint (strabismic amblyopia) or with unequal refractive errors (straight-eye amblyopia). Prevention requires an adequate screening programme that will detect the child with a visual defect early enough for effective treatment to be undertaken. School eye tests alone are too late; so preschool screening of all children should be introduced. How may we achieve this efficiently?

Our current methods of discovering children at risk depend on local authority child health clinics, health visitors, general practitioners, and school health services. At present when a child attending a health clinic is suspected of having a visual problem and specialist opinion is required generally this can be sought only with the family doctor's consent. In cases of possible squint it is sad but true that such consent is not always given. Possible reasons or excuses for this unhappy state of affairs are that the child is "too young," that "he may grow out of it," or that the hospital ophthalmic services are already grossly overloaded. Continuing education of doctors and health visitors will overcome the first two prejudices. A new approach is necessary to answer the problem of overburdened hospital ophthalmic services.

State-registered orthoptists are skilled in the examination of young children's eyes. Though accurate subjective testing of visual acuity in each eye is rarely possible before the 3rd birthday valuable information can be obtained by careful testing. Does the child appear to fixate a target binocularly? Do the eyes move to overcome the effects of a prism? Will he fixate an object with each eye separately with equal facility? Does he object to having one, but not the other, eye covered?

Orthoptists are the best people to be doing this work. They are expert in dealing with small children, and are particularly likely to diagnose a squint, of however small an angle. Recently Ingram ${ }^{1}$ has shown that an atropine refraction examination of young children can be used predictively to identify children who may develop esotropia or straight-eye amblyopia. Such a refraction check could also be undertaken by orthoptists, who would need little extra training to be able to perform this test. The fact that there are only some 700 State-registered orthoptists for the whole country does not seem to make the proposal so out of the question when it is realised that this is almost exactly twice the number of consultant ophthalmologists.

Over the past 20 years several pilot schemes using orthoptists as initial vision testers have been tried with success in various parts of the country. The child may be referred by the health 
visitor or family doctor, or taken directly by parents once they become aware of the service. The orthoptist then decides either that there is no problem or that the child must be referred to the ophthalmologist.

With co-operation from orthoptists visual screening of all children would become possible in line with the Court report programme for basic surveillance. ${ }^{2}$ The success of such a scheme would depend on several features. Firstly, a review of visual development at 8 months of age by the child health visitor, who would have received extra training in orthoptic techniques. Secondly, testing for visual defects of one or both eyes and for a squint would be performed at $2 \frac{1}{2}$ to 3 years of age by orthoptists, with an atropine refraction at this stage. Thirdly, these tests would be repeated at 4 to $4 \frac{1}{2}$ years of age by orthoptists. Finally, the annual school vision examinations by nurses or health visitors would also be continued. Naturally any child, however young, who is suspected of having visual difficulties would be entitled to appropriate vision testing and treatment as at present. A positive family history of squint or "lazy" eye is still an important indicator for early check ing of children.

If such a scheme were introduced, then the early detection of visual problems would allow the major part of the treatment to be carried out before the child starts school at 5 . The challenge of providing an integrated child health service, at least with regard to vision, can be met. The workers and the methods are available. We must try to ensure that there is a proper administrative structure for these plans to come to fruition.

\footnotetext{
${ }^{1}$ Ingram, R M, British fournal of Ophthalmology, 1977, 61, 4.

2 Committee on Child Health Services (chairman, Professor S D M Court), Fit for the Future. London, HMSO, 1976.
}

\section{Helping mothers to love their babies}

Only 15 years ago a student could qualify as a doctor without having given much thought to the idea that parents might harm their own children. Today all who work with children, and most of those who do not, are fully familiar with the concept of "battered babies" or "non-accidental injury." Dealing with such injuries is now part of the routine of a paediatrician's life and an informed guess at the incidence of chronic neurological handicap in children from this cause in the United Kingdom has produced a figure of about 400 new cases each year. ${ }^{1}$ Although some non-accidental injuries may have been missed in the past, it seems unlikely that increased awareness of the problem wholly accounts for the rapid increase in apparent incidence. What has gone wrong? Why do parents harm their own children ? Can we suggest any possible ways of promoting better parental caring behaviour?

Klaus and Kennell have recently summarised what we know of the factors which may be important in forming bonds between infants and parents, and their review has important implications for anyone working with newborn babies and their mothers. ${ }^{2}$ Most studies on this subject have concerned mother and baby, but we must not forget the importance of father to baby attachment.

Babies who have been separated from their mothers after birth because of prematurity or illness are more often the subjects of later physical abuse or failure to thrive without organic cause than those who have not been separated. Observations in animals have shown that rejection of the young by the mother is common when mother and baby are separated soon after birth. In the goat, for instance, the first 10 minutes after birth is critical to the mother's acceptance of the kid. In primates the critical period appears to be longerone or two days.

Studies with human mothers and babies have also shown that intimate contact in the early days after birth is supremely important in determining the future relationship between mother and child. In Cleveland, Ohio, two groups of mothers were studied. The first group had brief contact with their babies soon after birth and again at about six hours and then bottle fed them every four hours with no contact between feed times. The second group were given their babies for an hour soon after birth and had five hours of extra contact on each of the first three days. The mothers and babies were observed at one month, ${ }^{3}$ one year, ${ }^{4}$ and two years ${ }^{5}$ and on each occasion the mothers in the second group showed evidence of closer attachment to their babies. At one month they spent more time during feeds fondling their babies and looking at them face to face, and were less inclined to go out leaving the baby with someone else. They appeared to take more interest when the baby was being examined by the doctor. Similar differences persisted at one year, and at two years there was a significant difference in speech patterns between the two groups of mothers when talking to their children. The mothers who had had extended contact with their newborn babies used more varied and complex speech patterns, asked more questions of their children, and issued fewer commands.

The same workers have also studied the behaviour of mothers on first contact with their babies, looking for evidence of species-specific behavioural patterns which it may be necessary to encourage to promote normal mother to baby attachment. ${ }^{6}$ Mothers in hospital presented with their naked babies soon after birth will usually begin by touching the baby's limbs with their fingers and later progress to holding the trunk with their palms. This sequence of events is delayed if the baby is clothed. In addition to this touching and holding of the baby, direct eye to eye contact appears to be important.

The newborn infant can fix his eyes on a face very soon after birth, and many mothers find this response extremely rewarding and important in enabling them to relate to the baby as a person. Observations at home deliveries have shown maternal behaviour to be different from that in hospital. At home, the mother is much more in charge: immediately after delivery she often seems to be elated, and some mothers have described sensations similar to orgasm then. She is more likely to hold her baby in her arms and to explore his face with her fingertips. She may put the baby to the breast soon after birth, when he will lick and mouth at the nipple-imbibing mother love, not milk.

Clearly we need to review our present practices in many newborn nurseries. In some, pressures of work and the limitations of present accommodation make it difficult to adhere to an ideal policy. Nevertheless, the fall in birth rate should give midwives more time to devote to these matters. Thus the baby should be shown briefly to the mother immediately after birth. She should then be allowed to rest while the placenta is delivered and any necessary stitching done. After that, if they wish, both parents should be allowed to be alone with their baby in private for between 30 and 45 minutes (the father having witnessed the birth). During this time, the mother should be allowed to hold her naked baby to her under a heat shield and may put the baby to the breast if she wishes. 